\title{
Effect of noise on priming in a lexical decision task
}

\author{
MURRAY SINGER, DAVID M. BRONSTEIN, and JAYE M. MILES \\ University of Manitoba, Winnipeg, Manitoba R3T 2N2, Canada
}

The study was designed to assess the impact of arousal, induced by white noise, upon priming in lexical decisions. The subjects classified letter strings as words or nonwords. "Priming effect" refers to the fact that it takes less time to classify "butter" as a word after making a decision about a related word, like "bread," than after classifying an unrelated one, like "nurse." Two hypotheses were compared. (1) The debilitation hypothesis stated that noise would impair all lexical decisions, raising classification times. (2) The enhancement hypothesis stated that arousal (noise) biases the sampling of information toward "dominant" sources, increasing the priming effect. Neither hypothesis received support from the data. Instead, the impact of noise was as follows: Targets were slower than their preceding primes with noise, but there was no difference without it. This interaction suggests that noise makes it difficult to traverse lexical memory from one node to another, regardless of the relatedness of target to prime.

The spreading-activation model of lexical memory has received extensive attention since its original presentation (Collins \& Loftus, 1975; Quillian, 1968). In this view, the concepts corresponding to the words of a language are represented as nodes in a hierarchically structured network. The written or auditory appearance of a word activates its node in the network; permitting the retrieval of its semantic properties. When a node is so accessed, activation spreads automatically to adjacent nodes, which, in lexical memory, represent semantically related words.

Evidence for the spread of activation in semantic networks has been provided in numerous studies. Collins and Quillian (1969) found that verification time is greater for "distal" category statements, like "a tulip is a plant," than for "close" ones, like "a tulip is a flower." They argued that activation needs to cross more links in the network in the former case.

Freedman and Loftus (1971) asked their subjects to name an instance of a category that began with a given letter or was described by a given adjective (e.g., fruit-yellow). They reported that responses were faster when the category was provided first than when the letter or adjective was. Collins and Loftus (1975) argue that when the category name is provided first, activation can spread to and raise the excitation level of nodes corresponding to the category members. The category name is said to "prime" the possible responses.

This research was supported by Grant A9800 from the Natural Sciences and Engineering Research Council of Canada to the first author. These data were presented at the meeting of the American Psychological Association, Montreal, September 1980. We would like to thank Ely Kozminsky for his helpful comments about the manuscript. Requests for reprints should be addressed to M. Singer, Department of Psychology, University of Manitoba, Winnipeg R3T 2N2, Canada.
Meyer and his colleagues (e.g., Meyer \& Schvaneveldt, 1971; Schvaneveldt, Meyer, \& Becker, 1976) have reported a robust priming effect in a word-nonword classification task. It takes less time, for example, to recognize "butter" as an English word when it follows a closely related one, "bread," than when it follows an unrelated one, "nurse." Schvaneveldt et al. (1976) considered the possibility that priming occurs as a function of a "passive" spread of neural excitation. In the realm of fact retrieval, Anderson (1976) has reported that the time needed to recognize a fact increases as a function of the number of connections existing between the concepts in the fact and other facts in the learned set. Anderson's explanation of this "fan" effect is that the strength of activation spreading along a link is inversely proportional to the number of links activated by the node in question. Finally, Ratcliff and McKoon (1978) have demonstrated a large and reliable priming effect in the internal representation of sentence meaning.

One appealing feature of the concept of spreading activation is that it is consistent with what we know about the brain. The brain consists of neurons, groups of which can conceivably represent meaning in their patterns of activity and inactivity (Hebb, 1955). Information passes among neurons along their fibers. Because of this, it is reasonable to ask about the effect of changes in the level of neural excitation upon memorial phenomena. In particular, the goal of the present study was to examine the influence of an increase of neural arousal upon priming.

It is not possible to make a simple assertion about the influence of heightened arousal upon cognitive processes. In his review paper, Eysenck (1976) discusses reports of both facilitative and impairing effects of arousal. He discusses considerable evidence that items learned under 
conditions of high arousal in a paired associate task are recalled better after an interval of $20 \mathrm{~min}$ than corresponding low-arousal items are. On the other hand, Eysenck (1976) cites James' (1890) observation that it is sometimes difficult to retrieve information from memory when one is highly motivated to do so. In this vein, Eysenck (1974) reported that introverts were able to generate relatively few instances of a specified category under conditions of transient arousal. He argued that the poor performance was associated with an especially high level of arousal resulting from the summing of the transient arousal with the introverts' chronically high arousal level.

Eysenck (1976) has identified at least two dimensions in the study of the relationship between arousal and memory: namely, arousal at input vs. output, and subject vs. item arousal. The present study is addressed only to the problem of item arousal at output. First, arousal was induced by means of white noise and, so, was not an inherent characteristic of the subjects. Second, in focusing upon priming in lexical memory, the learning of the relevant information was assumed to have taken place at an earlier time. Accordingly, the impact of arousal was assessed at the time of output.

That white noise induces neural arousal was documented by Podvoll and Goodman (1967) and has since been used to manipulate arousal in numerous studies (e.g., Bailey, Patchett, \& Whissell, 1978; Daee \& Wilding, 1977; Eysenck, 1975). Although few studies have applied white noise at output, it is possible to extract, from previous findings, two hypotheses with regard to the possible impact of arousal upon performance in the priming paradigm, particularly with reference to the word-nonword classification task. The debilitation hypothesis states that increased arousal will slow the processes of word recognition. It is consistent with the suggestions, discussed above, that arousal will generally impair cognitive processing. The rationale of this position is that the elevation of arousal above "normal" levels constitutes noise in the system. The effect of this noise would be to degrade the memory lexical network, analogous to the degrading of a physical stimulus (Sternberg, 1969). This would result in an increase in recognition latencies both of primed and unprimed words, but in a fashion that would not influence the magnitude of the priming effect.

The enhancement hypothesis is generally consistent with the notion that arousal has facilitative effects on processing. It is based upon indications that arousal biases the sampling of information toward "dominant" sources (Broadbent, 1971). With respect to the priming task, the suggestion is that, in the condition of elevated arousal, a disproportional amount of excitation is diverted toward closely associated nodes. In a priming study, this would result in faster recognition of related items and slower recognition of unrelated ones, or, in other words, an enhanced priming effect.

While the enhancement hypothesis is consistent with the views of Eysenck (1976), there is virtually no evidence in the literature that comments on the debilitation vs. enhancement distinction. In one experiment that is relevant, Eysenck's (1975) subjects were asked to decide whether a word constituted an instance of a category (e.g., vehicle-boat). For positive trials, instances were either high- or low-dominant exemplars. Eysenck found neither a main effect of white noise nor an interaction of white noise and dominance. All of Eysenck's test items, however, were exemplars of the category in question. He did not examine unrelated test items.

\section{METHOD}

\section{Subjects}

The subjects were 24 male and female introductory psychology students at the University of Manitoba, who participated for course credit. The subjects in the noise group were told that they could leave without losing credit if they found the noise too unpleasant. Four of them took this option, leaving 10 noise and 10 control subjects. All of the subjects were native speakers of English.

\section{Materials}

The materials consisted of 330 word and nonword letter strings, arranged in 11 blocks of 30 . In each block, there were three pairs consisting of one word and a related word (WR), three pairs consisting of a word and an unrelated word (WU), and six word-nonword pairs (WN). The first word of each pair will be called the prime, and the second will be called the target. With this arrangement, the primes were followed equally often by words and nonwords. The remaining six items of each block were six nonpaired nonwords, intended to raise the proportion of nonword responses. Any possible response bias resulting from the $1.5: 1$ ratio of words to nonwords was not of great concern, since the crucial test items were all words.

Item pairs and independent nonwords were randomly assigned in appropriate numbers to 1 of 11 blocks, and each was then randomly assigned a position within its block. (The two elements in each pair always appeared consecutively.) The blocks were then arranged in a single random order to form a list.

From the subjects' point of view, the list consisted not of pairs, but of independent letter strings. The stimuli were not presented in explicit pairs (cf. Meyer \& Schvaneveldt, 1971) in order to discourage the subjects from consciously attempting to generate words closely related to the prime.

The WR pairs, selected from the 1952 Minnesota Word Association Norms (Jenkins, 1970), consisted of a randomly chosen word and its closest associate. The WU pairs consisted of a random word and the highest associate of a different random word. Nonwords were constructed by replacing one or two letters of words chosen randomly from the norms, vowels replacing vowels and consonants replacing consonants. All nonwords were pronounceable and were from four to six letters long. The first 10 items of a sample block were as follows: SLIRT (independent nonword), DOCTOR NURSE (related pair), FLOWER QUABE (word-nonword pair), THOME (independent nonword), TREE NIZE (word-nonword pair), THIEF SMOKE (unrelated pair).

\section{Procedure}

The subjects were tested individually. Each subject was randomly assigned to one of the four conditions defined by the crossing of "yes" button (left or right hand) and noise (noise or control). Due to an error, 6 of the 10 noise subjects were assigned to the right "yes" button. There were five subjects in each of the control groups.

The subjects sat about $40 \mathrm{~cm}$ in front of a 12-in. video monitor. The display of the materials was controlled by a 
PDP-8/A minicomputer. At the beginning of each block, a fixation point appeared on the screen for $10 \mathrm{sec}$. One second after it disappeared, the first string was displayed. The subject pressed the "yes" or "no" button, depending on whether the string was an English word. The string remained visible for $3 \mathrm{sec}$ regardless of when the subject responded, and it was immediately replaced by the next string. After the 30 strings of a block were displayed, there was a 1-min rest period.

The subjects were urged to respond as quickly as possible without error. They were told that they would be counted wrong if they did not respond in the 3-sec period during which the string was on the screen.

The first block constituted practice, and the resulting data were not examined. Practice was not explicitly distinguished for the subjects.

Continuous white noise was presented at $80 \mathrm{~dB}$ for the noise subjects. The noise was produced by a Grason-Stadler noise generator (Model 455) located in the test room, and it was amplified by a Sony tape recorder. The loudness measurement was made at the location of the subject's chair, using a Simpson sound-level meter (Model 886).

\section{RESULTS}

The data of principal concern were the correct response latencies of the targets of the WR and WU pairs. The error rate on words from these pairs was .012 . A preliminary analysis revealed mean latencies of 725 and $788 \mathrm{msec}$ for the unrelated and related primes, respectively $[\mathrm{t}(18)=1.54, \mathrm{p}<.15]$. Due to this considerable difference, the data analysis referred to the response latencies for the prime words as well as the targets. This procedure can be explained with reference to Table 1 , which shows hypothetical data. The classification of the unrelated target, "nurse," is shown to be $25 \mathrm{msec}$ slower than its prime, whereas the related target, "dog," is $75 \mathrm{msec}$ faster than its prime. If these values represent their conditions, it can be argued that the priming effect is not $50 \mathrm{msec}(800-750)$, but, rather, $100 \mathrm{msec}[25-(-75)]$.

Analysis of variance was applied to the correct response latencies, with noise and "yes" button acting as between-subjects variables, and role (prime vs. target), relatedness, and trial block (1-10) as the within-subjects variables. Because the latencies for error trials were missing, the analysis was applied to the subjects' mean scores on each block for each of the role by relatedness conditions. An $\alpha$ level of .01 is used except when otherwise noted.

It is useful to consider the effects that are predicted by the debilitation and enhancement hypothesis. The debilitation hypothesis states that arousal will slow

Table 1

Hypothetical Prime and Target Response Latencies (Milliseconds)

\begin{tabular}{|c|c|c|c|c|c|}
\hline \multirow[b]{2}{*}{$\begin{array}{l}\text { Related- } \\
\text { ness }\end{array}$} & \multicolumn{2}{|c|}{ Prime } & \multicolumn{2}{|c|}{ Target } & \multirow[b]{2}{*}{$\begin{array}{r}\text { Target- } \\
\text { Prime RL }\end{array}$} \\
\hline & RL & $\begin{array}{c}\text { Sample } \\
\text { Word }\end{array}$ & RL & $\begin{array}{l}\text { Sample } \\
\text { Word }\end{array}$ & \\
\hline $\begin{array}{l}\text { Unrelated } \\
\text { Related }\end{array}$ & $\begin{array}{l}775 \\
825\end{array}$ & $\begin{array}{l}\text { bread } \\
\text { cat }\end{array}$ & $\begin{array}{l}800 \\
750\end{array}$ & $\begin{array}{l}\text { nurse } \\
\text { dog }\end{array}$ & $\begin{array}{r}25 \\
-75\end{array}$ \\
\hline
\end{tabular}

Note $-R L=$ response latency.
Table 2

Mean Correct Response Latencies (Milliseconds) as a Function of Noise, Role, and Relatedness

\begin{tabular}{llcccc}
\hline & & \multicolumn{4}{c}{ Role } \\
\cline { 3 - 6 } & & \multicolumn{2}{c}{ Prime } & \multicolumn{2}{c}{ Target } \\
\cline { 3 - 6 } Noise & Relatedness & Mean & SD & Me.an & SD \\
\hline \multirow{2}{*}{ Noise } & Unrelated & 716 & 180 & 845 & 195 \\
& Related & 774 & 180 & 781 & 208 \\
\multirow{2}{*}{ Control } & Unrelated & 735 & 212 & 828 & 201 \\
& Related & 803 & 229 & 737 & 205 \\
\hline
\end{tabular}

Table 3

Mean Correct Response Latencies Illustrating Interactions Involving the Role Variable

\begin{tabular}{llcc}
\hline & & \multicolumn{2}{c}{ Role } \\
\cline { 3 - 4 } Variable & Level & Prime & Target \\
\hline \multirow{2}{*}{ Relatedness } & Unrelated & 725 & 837 \\
& Related & 788 & 759 \\
\multirow{2}{*}{ Noise } & Noise & 745 & 813 \\
& Control & 769 & 783 \\
\hline
\end{tabular}

recognition uniformly across conditions. One would expect, then, a main effect of noise. In this view, noise should not affect the priming effect. The priming effect itself is reflected by the Role by Relatedness interaction.

The enhancement hypothesis, in contrast, states that the priming of a target should be greater in conditions of elevated arousal. This hypothesis particularly predicts a Role by Relatedness interaction, and also a Noise by Role by Relatedness interaction.

The blocks variable was not considered to be of interest, since the list was presented to subjects in one fixed order, confounding block serial position and materials. Analysis of variance, furthermore, revealed no effects of "yes" button except two interactions involving the blocks variable. For these reasons, Table 2 shows the mean correct response latencies, collapsing across blocks and "yes" button. The only main effects were those of role $[\mathrm{F}(1,16)=19.4, \mathrm{MSe}=17,291]$ and block $[F(9,144)=2.19, \mathrm{MSe}=24,698, \mathrm{p}=.026]$. The role effect reflected mean latencies of $757 \mathrm{msec}$ and $798 \mathrm{msec}$ for primes and targets, respectively. The Role by Relatedness interaction was significant $[F(1,16)=$ $63.5, \mathrm{MSe}=15,140]$. The means for this interaction are in the upper part of Table 3. Tests of simple main effects showed that unrelated targets took $112 \mathrm{msec}$ longer to recognize than their primes $[\mathrm{F}(1,16)=38.7$, MSe $=$ 16,216], whereas related targets were $29 \mathrm{msec}$ faster than their primes $[F(1,16)=5.19, \quad M S e=16,216$, $\mathrm{p}<.05$ ]

Role also interacted with noise $[F(1,16)=8.36$, MSe $=17,291]$. Targets were $68 \mathrm{msec}$ slower than primes in the arousal condition $[\mathrm{F}(1,8)=13.8, \mathrm{MSe}=$ $17,291]$ and a nonsignificant $14 \mathrm{msec}$ slower in the control condition $(F<1)$. The means for this interaction are shown in the lower part of Table 3.

In addition, five interactions involving the block 
variable reached significance with $p<.02$. The Noise by Role by Relatedness interaction, which was of particular interest, did not approach significance $[F(1,16)=$ 1.11]. This corresponds to priming effects of 122 and $159 \mathrm{msec}$ in the noise and control conditions, respectively. In all, only 9 of the 31 effects examined in the analysis were significant.

\section{DISCUSSION}

Let us consider the implications of the effects that were measured. First, the priming effect, the sine qua non of this study, is reflected by the Role by Relatedness interaction. Unrelated targets were recognized slower than their primes, and related targets were recognized faster. The combined effect sums to $141 \mathrm{msec}[112-(-29)]$. This value is in reasonable agreement with the priming effects of 85 and $117 \mathrm{msec}$ measured by Meyer and Schvaneveldt (1971) in two experiments.

Second, how well do the results agree with the debilitation and enhancement hypothesis? The debilitation hypothesis predicts the appearance of a main effect of noise. This effect was not significant, with mean latencies of $779 \mathrm{msec}$ and $776 \mathrm{msec}$ in the noise and control conditions, respectively. The enhancement hypothesis, on the other hand, generates the prediction of a larger priming effect with heightened arousal. The corresponding interaction, Noise by Role by Relatedness, did not approach significance. The priming effect was actually smaller in the noise than in the control condition. Neither hypothesis, then, has gained any support from these results.

The Noise by Role interaction, however, sheds some light on the impact of arousal upon lexical decisions. Table 3 shows that, in the noise condition, subjects needed more time to make a decision about a target than a prime. The comparable difference in the control condition was negligible. Arousal induced by noise seems to make it difficult to traverse the lexical network from prime to target, regardless of relatedness.

This interpretation leads to two other points. First, one might ask why decisions about primes were not likewise slowed in the noise condition. A tentative answer is that only one-third of the primes were preceded by words, as compared with $100 \%$ of the targets. It is posited that arousal does not make it difficult to enter the lexical network, but rather to move from one node to another.

The second point concerns the fact that decisions about primes were faster than for targets. It may well be that this main effect is simply a by-product of the Noise by Role interaction, and the elevated latencies of the noise targets in particular.

From the outset, it has been asserted that the automatic spread of activation is the mechanism that underlies the priming effect. Neely (1977), however, has presented convincing evidence that retrieval of information from lexical memory is governed both by spreading activation and by a slower acting attentional mechanism. The latter mechanism comes into play, for example, when a person voluntarily concentrates on a particular concept, as might be the case when one attempts to name several breeds of dog. Future work on the present problem will need to ask whether $i$ t is spreading activation, the attentional mechanism, or both that receive the impact of noise is a lexical decision task. This might be accomplished by varying the stimulus-onset asynchrony (SOA) between prime and target from values below to well above $.75 \mathrm{sec}$ (the present SOA was $3 \mathrm{sec}$ ). The reason for this is that Neely (1977) has shown that the major role of spreading activation occurs for SOAs less than $.75 \mathrm{sec}$, whereas that of the attentional mechanism occurs for greater SOAs.

The sizable, although statistically marginal, latency difference between the unrelated and related prime words suggests a caveat with regard to research concerning the priming effect. It states that one should be concerned not only with target latencies, but also with the latency difference between targets and their corresponding primes.

In summary, we set out to examine the impact of heightened arousal upon lexical decisions. The results showed that the familiar priming effect remains intact in conditions of noise but that decisions about target words, in relation to their primes, is slowed by noise. Future studies will need to determine whether the effect of noise is exerted upon the process of spreading activation or a limited-capacity conscious attention mechanism.

\section{REFERENCES}

Anderson, J. R. Language, memory, and thought. Hillsdale, N.J: Erlbaum, 1976.

Bailey, G., Patchett, R. F., \& Whissell, C. M. Effects of noise on accuracy, visible volume, and general response production for human subjects. Perceptual and Motor Skills, 1978, 46, 76-78.

Broadbent, D. E. Decision and stress. New York: Academic Press, 1971.

Collins, A. M., \& Loftus, E. F. A spreading-activation theory of semantic processing. Psychological Review, 1975, 82, 407-428.

Collins, A. M., \& Quillian, M. R. Retrieval time from semantic memory. Journal of Verbal Learning and Verbal Behavior, $1969,8,240-247$.

Daee, S., \& Wilding, J. M. Effects of high intensity white noise on short-term memory for position in a list and sequence. British Journal of Psychology, 1977, 68, 335-349.

EysEnCK, M. W. Extraversion, arousal, and retrieval from semantic memory. Journal of Personality, 1974, 42, 319-331.

EySENCK, M. W. Effects of noise, activational level, and response dominance on retrieval from semantic memory. Journal of Experimental Psychology: Human Learning and Memory, 1975, 2, 143-148.

Eysenck, M. W. Arousal, learning and memory. Psychological Bulletin, 1976, 77, 389-404.

Freedman, J. L., \& Loftus, E. F. Retrieval of words from longterm memory. Journal of Verbal Learning and Verbal Behavior, 1971, 10, 107-115.

HEBB, D. O. Drives and the C.N.S. (conceptual nervous system). Psychological Review, 1955, 62, 243-254.

JAMES, W. The principles of psychology. London: Macmillan, 1890.

Jenkins, J. J. The 1952 Minnesota word association norms. In L. Postman \& G. Keppel (Eds.), Norms of word association. New York: Academic Press, 1970.

Meyer, D. E., \& Schvaneveldt, R. W. Facilitation in recognizing pairs of words: Evidence of a dependence between retrieval operations. Journal of Experimental Psychology, 1971, 90, 227-234.

NeELY, J. H. Semantic priming and retrieval from lexical memory: Roles of inhibitionless spreading activation and limited capacity attention. Journal of Experimental Psychology: General, 1977, 3, 226-254.

Podvoll, E. M., \& Goodman, S. J. Averaged neural activity and arousal. Science, 1967, 155, 223-225.

Quillian, M. R. Semantic memory. In M. Minsky (Ed.), Semantic information processing. Cambridge: M.I.T. Press, 1968.

Ratcliff, R., \& McKoon, G. Priming in item recognition. Journal of Verbal Learning and Verbal Behavior, 1978, 17, 403-417.

Schvaneveldt, R. W., Meyer, D. E., \& Becker, C. A. Lexical ambiguity, semantic context, and visual word recognition. Journal of Experimental Psychology: Human Perception and Performance, 1976, 2, 243-256.

Sternberg, S. Memory scanning: Mental processes revealed by reaction-time experiments. American Scientist, 1969, 57, $421-457$.

(Received for publication August 13, 1981.) 